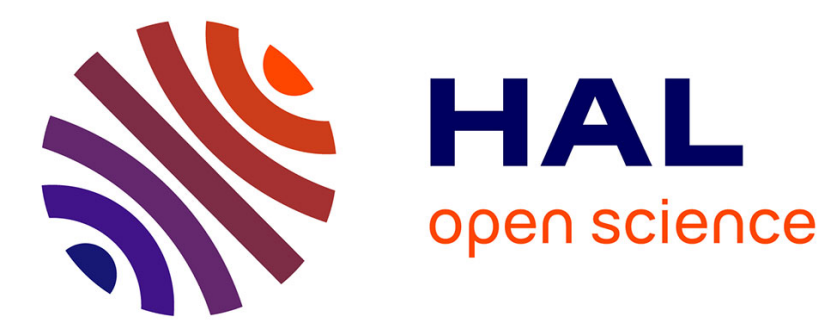

\title{
The Paradox of Sensemaking in Organizational Analysis
} Florence Allard-Poesi

\section{To cite this version:}

Florence Allard-Poesi. The Paradox of Sensemaking in Organizational Analysis. Organization, 2005, 12 (2), pp.169-196. 10.1177/1350508405051187 . hal-01251211

\section{HAL Id: hal-01251211 \\ https://hal.science/hal-01251211}

Submitted on 8 Jan 2016

HAL is a multi-disciplinary open access archive for the deposit and dissemination of scientific research documents, whether they are published or not. The documents may come from teaching and research institutions in France or abroad, or from public or private research centers.
L'archive ouverte pluridisciplinaire HAL, est destinée au dépôt et à la diffusion de documents scientifiques de niveau recherche, publiés ou non, émanant des établissements d'enseignement et de recherche français ou étrangers, des laboratoires publics ou privés. 


\title{
The Paradox of Sensemaking in Organizational Analysis
}

\author{
Florence Allard-Poesi \\ Université Paris-Est Créteil, Institut de Recherche en Gestion, France. \\ Organization, Volume 12(2): 169-196, 2005.
}

\begin{abstract}
Taking Weick's theory of sensemaking as illustrative of a socio-constructionist conception of sensemaking and learning in organization studies, we examine the methodological approaches used in this research. This analysis reveals that, although departing from the structurofunctionalist perspective of conventional cognitive theory, sensemaking research nonetheless aims to establish objective knowledge on these subjective processes. In so doing, it is faced with the interpretive paradox implied in seeking an "objective science of subjectivity".

Fully acknowledging that studying sensemaking is an active and subjective sensemaking process in itself implies that we re-engage in sensemaking processes. The postmodern route, on the one hand, invites us, through deconstruction, to engage against our sensemaking as a way of uncovering both the constitutive and the undecidable character of sensemaking activities. The pragmatist (or participative) route, on the other hand, suggests that, through participative action research, we fully engage in sensemaking with organization members and recognize the socially constructed aspect of all sensemaking activities. Though not without difficulties, these proposals encourage us to make sense differently of sensemaking processes in organizations.
\end{abstract}




\section{The Paradox of Sensemaking in Organizational Analysis}

The collective dimension of cognition and sensemaking has attracted a great deal of attention in Managerial and Organizational Cognition research since 1980, leading to numerous theoretical, methodological and empirical works on its characteristics, how it has emerged and how it functions in organizations. Collective sensemaking and representations are in fact considered to be crucial to our understanding of decision-making processes (Beyer, 1981), actions and performance (Huff, 1990; Thomas et al., 1993), and change and learning (Poole et al., 1989) in organizations. Initially considering this collective dimension of cognition mainly as a stable system of shared ideas (Beyer, 1981; Hedberg, 1981; Sproull, 1981), researchers are increasingly taking into account the process-based and socially constructed character of cognition and sensemaking in organizations.

Though relying on different theoretical backgrounds, researchers converge to see sensemaking and learning as created and situated in the micro-practices of interactions, conversations and coordinated actions between people (Easterby-Smith et al., 2000; Hellgren and Löwstedt, 2001), and as activating tensional dynamics: emergence and innovation processes together with the maintenance of generic subjectivity (Weick, 1995), the perpetuation of linguistic and work rules through their "competent" use in particular contexts together with their continuous redefinition and emergence through personal experience and judgements (Wenger, 2000; Tsoukas and Vladimirou, 2001), minority influence processes together with conforming and compliance behaviors (Weick, 1995), convergence and divergence (Wenger, 2000), conflict, dissonance and cacophony, together with homogeneity and consensus (Easterby-Smith et al., 2000). 
Such a socio-constructionist turn has implied a shift from individual, group or organizational levels of analysis to interactions. Research tends to focus on detailed, situated and concrete practices and interactions (implying analyses of conversation sequences, storytelling and narratives, Easterby-Smith et al., 2000), thus contributing to the linguistic perspective of organizational research (Alvesson and Karreman, 2000a). This is also accompanied by the adoption of micro/interpretivist methodological approaches such as participant observation, open interviews, conversational analysis, and interaction analysis.

Paradoxically enough, this socio-constructionist turn that pervaded both the theoretical and methodological approaches used in the study of sensemaking did not lead to epistemological reconsideration: reflections on the nature of the knowledge created on such processes are astonishingly absent. How do we study sensemaking in organizations? How do we make sense of the social-constructionist knowledge thus elaborated? Following Huff's (1997: 50) recommendations that we should "enlarge our epistemological perspective", this article aims to question and reflect on the nature of the knowledge created on sensemaking, along socioconstructionist lines.

Taking Weick's conception of sensemaking as illustrative of this socio-constructionist perspective, we examine the methodological approaches used in this research. This analysis reveals that sensemaking research relies extensively on grounded approaches that seek to grasp people's understandings and, through systematic comparison techniques, aim to reveal regularities and systematic associations in the structuring process of sensemaking and organizing. Sensemaking research consequently involves a fundamental paradox: it defines reality and meanings as socially constructed, yet it seeks to disengage from that experience and objectify it (Schwandt, 1994: 119).

Fully acknowledging that our sensemaking of the sensemaking process is an active, purposeful and subjective sensemaking process in itself is not an easy task. To paraphrase 
Weick (1999: 804), this implies in particular that we "drop our heavy [methodological, our addition] tools". As a beginning, we present two different routes that may enable us to reengage in sensemaking processes. The postmodern route, on the one hand, invites us, through deconstruction, to engage against our sensemaking as a way of uncovering both the constitutive and the undecidable character of sensemaking activities. The pragmatist (or participative) route, on the other hand, suggests that, through participative action research, we fully engage in sensemaking with organization members and recognize the socially constructed aspect of all sensemaking activities.

Though not without problems, these different proposals encourage us to reflect on how we make sense of sensemaking processes in organizations. Suggesting different approaches to the study of sensemaking, they contribute to the exercise of "disciplined reflexivity" that Weick $(1999 ; 2002)$ invites us to pursue.

\section{How People Make Sense in Organizations}

Departing from a structuro-functionalist perspective on cognition, researchers have increasingly developed socio-constructionist theories of sensemaking in organizations. Weick's conception of collective sensemaking and organizing $(1979 ; 1993 a ; 1995)$ is taken here as illustrative of such a socio-constructionist perspective.

Sensemaking may be defined as an ongoing accomplishment through which people create their situations and actions and attempt to make them rationally accountable to themselves and others (Weick, 1993a, 2001: 11). These processes are activated by and situated in the interactions that take place between members of organizations, where the kind of participation process that prevails, and the participants' representations of the situation and of the others, their various projects and activities, play a crucial role in the subjectivity and the collective 
understanding that will develop. Such a perspective on organizing and sensemaking may be considered as fully embracing an interpretive conception of social reality and human beings.

\section{Sensemaking is an invention}

Sensemaking activities involve the construction and bracketing of cues to be interpreted, linking them to a previous frame of reference that summarizes past experiences (such as traditions, ideologies, theories of actions or stories), and revising the interpretations that have thus developed as a result of actions, interactions and their consequences (Weick, 1995: 8). In this perspective, what people make sense of, and how they do it, depends on where they look, how they look, what they want to represent and their tools of representations (the phenomenological hypothesis, Schwandt, 1994). There is no "one best way" to represent reality, and even if there is some order 'out there' in the world, we can never be sure we have discovered it. For any situation, then, there are an indefinite number of useful, plausible representations, depending on the chosen level of description and modes of representation (Weick, 1993, 2001: 8-9).

The sensemaking perspective consequently insists that the meanings people develop and attach to their experiences are fundamentally fluid, unstable and idiosyncratic, and that there is no such thing as a common, unified or shared representation in organizations: individual histories are too diverse (Weick, 1995: 188), and influence processes are too complex and multiple (see Fiol, 1994; Allard-Poesi, 1998; 2001), to produce similarity. "So if people in organizations share anything, what they share are actions, activities, moments of conversations, and joint tasks, each of which they then make sense of using categories that are more idiosyncratic (Weick, 1995 : 188)”. 


\section{Sensemaking is for doing}

With interpretivists, the sensemaking perspective argues for a teleological, purposeful conception of human beings. Sensemaking activities refer to those means by which intentional agents faced with equivocality seek to "structure the unknown" (Waterman, 1990 : 41, in Brown and Jones, 2000 : 662): the self, others, and the world around them.

Sensemaking processes take place in the service of maintaining or restoring a consistent, continuous and positive self-conception (Weick, 1995: 23), which consists of a personal identity (that refers to person-specific attributes) and a social identity (that refers to social group memberships, Brown and Jones, 2000: 660). These identities are constituted out of the process of interactions and are partly shaped by the categories and concepts available in discourses. When engaging in various interactions and discourses, the "individual" has to decide which self is appropriate, which self to present to others. Based on the conduct of others, people enact these selves and define the situation and actions consistently, by projecting them into the environment and observing the consequences. If the outcomes do not confirm these enacted selves and definition of the situation, sensemaking processes recur, the individual re-enacts a self and redefines the situation and actions consequently (Brown and Jones, 2000; Weick, 1995).

McGinn and Keros's (2002) study shows that people engaged in dyadic transactions quickly coordinate a shared logic of exchange and that the level of cooperation of these improvisations (Weick, 1998) depends on the social ties (and therefore the related social identities) of the participants. 'Friends' nearly always improvise opening-up interactions and rely on a logic of full mutual honesty; 'Strangers' adopt a similar logic in face-to-face communications, but their modal improvisation is 'haggling' in e-mail communication. Since social ties affect the understanding of what is appropriate behavior in a seemingly straightforward transaction, interactions between strangers often lead to asymmetries: the two 
parties look at one another and the situation differently (one adopting a cooperative behavior, while the other behaves in a less forthcoming manner), so that they are not able to understand each other. These interactions result either in an impasse, or inequalities in payoff.

Although sensemaking is usually triggered by a failure to confirm oneself, this process does not have to be regarded as an existential question. Sensemaking is for "social doing": Any reflective act originates in a context where some projects are envisioned, others are under way and still others have just been completed (Weick, 1995: 26). Normally, when people act, their reasons for doing things are either self-evident or uninteresting (Weick, 1993a, 2001: 13). When this flow of actions is interrupted, and especially when these actions and projects cannot be easily disavowed or minimized, people feel compelled to make sense of what is happening. In organizational life, as people's individual projects and actions are dependent upon others' projects and actions (Weick, 1979), interruptions and sensemaking will mainly focus on these interdependent acts that help people to complete their various projects or hinder them from doing so.

When these interdependent actions are interrupted in the organization, the participants have to determine many things at the same time: What happened? What does it mean for the others and myself? What does it mean for my subsequent actions? As people usually have different projects under way at the time reflection takes place, and as those projects affect and are affected by personal self-conception, the situation becomes over-determined, equivocal. The sensemaker faces confusion.

In this context, "structuring the unknown" is a very pragmatic issue: I just need to know enough (about myself, the others and the situation) to get on with my (and therefore the others') projects (Weick, 1995: 29). People then need values, priorities about preferences, to help them to be clear about which projects matter, and this in turn will help them define the meaning of prior experience and actions. "Structuring the unknown" is also a social issue: as 
people's projects and actions are interdependent, they have to make sense together so they can be successfully defined and pursued.

Gioia et al.'s (1994) study of strategic change in academia nicely illustrates this process. The new President of the university studied appointed a Strategic Planning Task Force to design a strategic planning process that could make the university competitive in its future academic and economic environment. During early meetings, the members of the task force attempted to construct an identity for the group and an interpretation of their charge: who and what are we? What are we supposed to do? What does "strategic planning" mean? These efforts to reduce equivocality took place in a context where the participants developed ambivalent feelings about the President. They demanded autonomy but tried repeatedly to infer what the President and the other stakeholders wanted. They tried to figure out what their alternative courses of action might mean for others, and, as a result, slowly began to define their roles as "facilitators in helping to launch the change efforts". This perhaps excessively defensive identity was however insufficient to develop a clear framework of the strategic planning process, which incited and left room for the president's external intervention.

\section{Sensemaking is an ongoing and tensional process}

With interpretivists, the sensemaking perspective casts social reality as an ongoing construction elaborated through interactions, a fragile and temporary order that people continuously define and redefine through their actions and experiences (the interaction hypothesis, Schwandt, 1994). Following Mead and Blumer's symbolic interactionism, Weick considers that a system of organized actions is created and developed in interactions through which people invent and create their everyday life: "Organizations are built, maintained, and activated through the medium of communication" (Weick, 1990, $2001: 136$ ). 


\section{Intersubjectivity and the emergent organization}

Through everyday interactions and conversations, people may develop equivalent expectations around issues of common interest, a convergence that enables them to coordinate their actions (Weick, 1995: 74). Strongly rejecting the notion of collective cognition as a stable system of shared ideas, however, Weick $(1979 ; 1995)$ argues that common understandings of the aims and intentions of an organization by its members is unnecessary, and may even be detrimental for organized actions: all that is necessary is the cognition that permits organization members to mutually predict one another's behavior (Weick, 1979), that is, to develop "equivalent meanings". Through discussion, groping, trial and error, and sounding out, people share perceptions among themselves and gradually define or create meanings (Weick, 1995: 99) that enable them to agree on decisions and actions to undertake and thus to coordinate their actions. As people strive to share their feelings, intentions and thinking through face-to-face communication, they give rise to "vivid, unique intersubjective meanings" (Weick, 1995: 75).

\section{Generic subjectivity and the social structure}

This does not mean that sensemaking processes are only local, transitory or self-contained micro-productions. Interaction processes are shaped by language rules, by the vocabularies or frames that summarize past experiences and from which cues are extracted and made sensible, and by authority relations, work roles, norms and social structures that assign rights of and weight to interpretations and help render those cues meaningful (Weick, 1993a: 22; 1995: 71). The micro-activities of sensemaking activate and re-enact both the society and the "organization" within which the interactions are taking place.

This articulation of micro and macro levels is not conceived as a simple, causal or determinist relationship. Shared goals, roles and the system that requires them (the organization) are created and give substance as people invoke them to justify a collective structure and their 
interdependent actions, and treat the organization as if it was real (Knorr-Cetina, 1981; Weick, 1993a). When those meanings are created and maintained in common scripts, vocabularies, symbols, habituated action patterns and generic routines, a generic subjectivity arises, allowing substitutability among people (Weick, 1995: 71,74).

Research on sensemaking processes during disasters (Weick, 1990; 1993b; Gephart, 1997) shows how these reified rules, roles and systems are crucial resources for making sense of what is happening and knowing what to do as events unfold. Public inquiry research (see Gephart, 1993; Brown, 2000; and Jones, 2000) illustrates how testimonies and subsequent inquiry reports are centrally concerned with making sense of the organization or institution and re-establishing its legitimacy, these elements serving as basis for situating responsibility and blame.

In sum, organizing is defined as "a mixture of unique, vivid intersubjective understandings and understandings that can be picked up, perpetuated and enlarged by people who did not participate in the original intersubjective construction" (Weick, 1995: 72).

\section{Sensemaking as a tensional dynamic}

While both the intersubjective and the generic dimensions rely on and constitute each other (e.g. Weick's study of the Mann Gulch Disaster, 1993b), they also continuously endanger each other in the organization (e.g. Weick's study of Tenerife Air Disaster, 1990).

When a situation is perceived as highly equivocal, intersubjective processes are liable to prevail. People will express different and sometimes divergent viewpoints. As people strive to reach an agreement, the expression of minority and dissenting views will activate complex influence processes, conflict and negotiation dynamics between participants (Doise and Moscovici, 1994), and divergent thinking (Nemeth, 1997). If the divergences do not stem from incompatible norms and values, the negotiations are liable to give rise to unique, innovative answers (Eisenhardt et al., 1997; Allard-Poesi, 2001). These answers may call 
into question the "social structure" as represented and defended by the majority and may lead, temporarily at least, to less social order and more confusion.

If the situation is perceived as a "normal", routine one, people will rely on assembly rules, procedures, instructions or recipes used in the organization to deal with the problem. They may not feel very committed to any particular position regarding the issue, or if they do, may censor themselves (either because they think the others agree with the dominant answer, or because formal procedures impede the expression of their divergent viewpoints, Doise and Moscovici, 1994). Generic subjectivity, taking in particular the form of the majority answer or of a compromise consensus to which nobody really adheres, will tend to prevail (Janis's Groupthink), at the expense of innovative answers.

If the intersubjectivity and generic subjectivity of sensemaking rely on and constitute each other, they may also deny and destroy each other (see Weick, 1990, 2001: 116-117). These elements give rise to a complex, precariously balanced, and highly tensional conception of collective sensemaking in organizations.

Sensemaking's focus on the meanings people attach to the situations they encounter, on their various "projects", and on the highly tensional processes that take place during their interactions, may be understood as fully embracing an interpretive perspective on social reality and social actors. With interpretivists, however, this socio-constructionist perspective on sensemaking encounters the paradox of seeking an "objective interpretive science of a subjective human experience" (Schwandt, 1994: 119).

Here we turn to the methodological approaches used in sensemaking research to examine how we make sense of sensemaking processes in organizations. 


\section{How We Make Sense of Sensemaking Processes}

In accordance with a phenomenological perspective on social reality, researchers studying sensemaking focus on the idiosyncratic and intersubjectively created meanings that people attach to their experiences. "Observers mobilize a set of methodological tools that enables them to deal with meanings rather than frequency counts. Methodologies are assembled in the service of gaining access to the situated generation of some kind of explanation for an unexpected interruption" (Weick, 1995: 173). Following the interpretivist project (Schutz, 1967), these first-order understandings of people's meanings are used to develop an interpretive, grounded theoretical understanding of sensemaking processes "hovering low over the data".

Here we analyze the methodogical approaches used in sensemaking research. The empirical studies have been selected on the following grounds: 1/ They are primarly concerned with studying sensemaking processes, $2 /$ their conceptual underpinnings rely (partly at least) on Weick's theoretical framework, 3/ the other conceptual frameworks used ${ }^{\mathrm{i}}$ are consistent with the socio-constructionnist conception of sensemaking developed by Weick. The selection was aimed at illustrating a wide variety of research methodologies and design and not at representing faithfully the actual methodological practices of this research.

This careful (if not exhaustive) analysis of these methodological approaches to sensemaking shows that they may be seen as in contradiction with the interpretive conception of social reality they seek to uncover. Roughly speaking, with interpretivism, sensemaking research seeks to develop an 'objective social science of subjectivity'.

Our intention here is neither to say that all sensemaking research falls into this paradox ${ }^{\mathrm{ii}}$, nor to pretend that this account objectively describes sensemaking research processes. We are conscious that we are objectifying/reifying research processes and approaches that are much 
more diverse and complex (see Weick, 1995: 172-173 for another review). What we mainly want to underline are the practical consequences of the sensemaking search for objectivity: that in seeking to disengage itself from subjective experience and objectify it, sensemaking research undermines, and may even lose, the fluid, tensional, and fundamentally problematic view of sensemaking and organizing it attempts to convey.

\section{Grasping people's meanings}

Celebrating the permanence and priority of the real world of the first person and subjective experience, sensemaking research focuses on detailed, situated and concrete practices and interactions in organizations. This is accompanied by the adoption of micro/interpretivist data gathering techniques that aim to grasp the meanings that people attach to themselves, to others, to their experiences and the situations they encounter.

Gioia et al.'s (1991; 1994; 1996) studies of sensemaking during strategic change in academia rely on participant observation, open interviews, recordings and transcripts of the meetings of the task force, and documentation related to its actions. Open in-depth interviews with each participant are used to infer the subjective interpretations associated with the participants' experiences (Gioia et al., 1994: 368). Participants are encouraged to use their own terminologies and to steer the interview around issues and concepts they feel best represent their own experiences (Gioia et al., 1996: 379). The participant-observer, nominated as a member of the task-force, was allowed to participate in and tape all deliberations. This enabled him to get "as close as possible to the data and to have direct experience with the meanings and perspectives of the participants" (Gioia et al., 1994: 368).

Thomas et al. (2001) studied a unique small organization, whose purpose is to facilitate strategic knowledge distillation in the U.S. Army. Relying on the logic of theoretical sampling (Glaser and Strauss, 1967), they selected staff and leaders from the different areas of 
the organization to provide a wide range of perspectives, and conduct semi-structured interviews with the aim of getting 'thick descriptions' of events and procedures in the organization. Archival data (in the form of newsletters, instructional videos, vignettes etc.) were also collected to get additional insight into the knowledge-based technologies used in the organization.

When a study is aimed at understanding the micro-logics and activities of sensemaking that take place between organization members, research favors records and transcripts of interactions (face-to-face or via e-mail) (e.g. Fiol, 1994; McGinn and Keros, 2002; AllardPoesi, 2001). McGinn and Keros (2002) recorded, transcribed and coded 87 dyadic interactions to investigate how social ties and communication media affect the logic of exchange governing transactions. Using a similar approach, Allard-Poesi (2001) studied how participants in a small group working on safety problems at the workplace dealt with their divergences and conflicts during their interactions, and evaluated the impact of these negotiation processes on the consensus developed.

The textual approach developed by Gephart $(1993 ; 1997)$ for investigating sensemaking processes during public inquiry into accidents relies on a detailed, computer-supported analysis of official proceedings (that records all inquiry testimonies) and of other related documents (field notes, company documents, newspaper articles). This approach is designed to understand the micro-practices, language rules and resources people use and create to make sense of their world, and to show how those resources and rules are made meaningful to participants by previous conventions and rules. Gephart (1993) first sampled, on theoretical grounds, the textual data to be analyzed, then conducted a fine-grained, expansion analysis of key testimonies and related documents. This analysis showed how the participants in an inquiry into an accident tried to negotiate (sometimes unsuccessfully) formal schemes of authority, responsibility, rules and policies in order to situate responsibility. Using a similar 
approach, Gephart (1997) showed how different groups use different vocabularies and schemes, and attribute different roles and significations to quantitative measures for evaluating hazards in the organization.

When direct access to interaction data is not possible, archival data (Orton, 2000) and inquiry reports (Brown, 2000; and Jones, 2000) are used. Those are considered either as more or less true accounts of the sensemaking process that took place during the events they describe (Weick, 1993b; Orton, 2000) or as an artifact resulting from previous authorial strategies to present an understanding of events (Brown, 2000). In both cases, particular attention is paid to the singular, idiosyncratic meanings that the "documents" convey and to their dynamics as the events unfold.

As symbolic interactionists (Blumer, 1969) and interpretivists, sensemaking researchers consider that, whatever the subject of research, the participants' points of view are essential: it is through the meanings and the symbols they use and create from social interactions and communications that they produce their world and reality (Weick, 1995: 41). Accordingly, the research uses data-gathering techniques intended to represent or be sensitive to the diversity and dynamics of meanings in organizations. This research program requires the researcher to actively enter the world of the people being studied in order to see the situation as it is seen by the actors and observe what they take into account, how they interpret what they take into account (Blumer, 1969: 56), how they behave and interact, and in what context (Schwandt, 1994: 124).

\section{A person who grasps at too much may lose everything.}

The focus of this research on the micro-practices of sensemaking may be said to sometimes rely on too muscular a conception of discourses and practices (Alvesson and Karreman, 2000b: 1131), where what people say or do necessarily refers to, informs or frames what they 
mean (their representations, subjectivities and perceptions). Social psychology warns us against such a powerful and transparent conception of discourse: compliance behaviors, compromise consensus and groupthink are well known collective phenomena where participants' idiosyncratic conceptions and meanings are coupled loosely if at all with their public behaviors and discourses. This is not to say that the conversations and interactions people engage in have no effects on their subjectivities and meanings. But these effects may be uncertain, weak and temporary (Alvesson and Karreman, 2000b: 1133). Grasping people's meanings may then become a much more difficult task than it appears: "Intead of embracing the increasingly popular view of discourse as constituting reality and subjectivity one may be more careful in one's assumptions" (Alvesson and Karreman, 2000b: 1132).

The very idea of 'grasping' is also highly problematic. The understanding of people's meanings (the development of a first-order understanding) involves theoretical sampling operations and/or constant comparison techniques. Through theoretical sampling, the researcher selects the data of specific groups or themes that will be subjected to subsequent analysis. S/he "extracts cues" from the flow of the data, on the basis of an emerging or previous theoretical frame (see Gephart, 1993; 1997; Thomas et al., 2001). When all data are analyzed, the researcher conducts a grounded, first-order analysis (see Gioia et al., 1994; 1996; Thomas et al., 2001). Following interpretive guidelines (Van Maanen, 1979; Spradley, 1979), this consists of: 1/ selecting sections from the data, 2/ identifying key terms as provided by the informants, and 3/ through constant comparison (Glaser and Strauss, 1967; Strauss and Corbin, 1990), developing in vivo codes, first-order categories that supposedly reflect the informants' natural categorization, shared concepts and processes.

Whether these first-order terms and categories are 'grounded in' and 'emerging from' the data, and so reflect or represent the meanings people attach to their experiences, is highly questionable. As organization members, the researchers' sensemaking process consists of 
"the construction and bracketing of cues" from the flow of their experiences, looking for commonalities, shared ideas and patterns; and these operations are necessarily shaped and informed by the researchers' previous frames.

Although this construction process is inescapable (Alvesson and Sveningsson, 2003: 967968), the problem arises as the researcher, using theoretical sampling and/or constant comparison analytical methods, argues that (or acts as if) the first-order categories developed represented people's actual perceptions and representations. A variety of techniques are in fact employed to support this claim: multiple interviews with the same informants (e.g. Gioia et al., 1996), members' checking (e.g. Thomas et al., 2001), multiple coding (by different coders, e.g. Gioia et al., 1994; McGinn and Keros, 2002; Allard-Poesi, 2001; Fiol, 1994, or use of different analytical schemes, e.g. Gioia et al., 1996; Thomas et al., 2001), computersupported analysis (Gephart, 1993; 1997).

This objectifying aspect of sensemaking research is also present when the researcher seeks to develop a second-order understanding of what s/he observes.

\section{Developing a grounded understanding}

Sensemaking research from the interactionist perspective requires entering the world of the informants, taking the point of view of those studied, and understanding the situated character of interactions so as to develop a second-order interpretation, an interpretive theory grounded in first-hand data (Denzin, 1970). This second-order interpretation is achieved through constant comparison (Glaser et Strauss, 1967; Strauss and Corbin, 1990; Lincoln et Guba, 1985), analytic induction (Goetz and LeCompte, 1981; Lincoln et Guba, 1985) or other analytical techniques relying on a priori coding schemes (e.g. Huberman et Miles, 1984).

Through constant comparison, first-order informants' categories, once developed, are assimilated into a set of second-order categories and dimensions. This grouping at a more 
theoretical level is aimed at "capturing the informants' categories at a higher level of abstraction" (Gioia et al., 1996: 375), "discerning general patterns in the data" (Gioia et al., 1994: 371), and "developing conceptual relationships among major concepts and emerging themes" (Thomas et al., 2001). Such a multi-stage process represents an attempt to give a balanced voice to both the insiders and the researchers" views and "to allow insights to emerge without force-fitting them into (a) prior theoretical perspective" (Gioia et al., 1994: 380).

Analytic induction involves scanning the data for categories of phenomena, developing working typologies and hypotheses among such categories upon an examination of initial cases, then modifying them on the basis of subsequent cases (Goetz et LeCompte, 1981: 57). Negative instances are consciously sought in order to expand, adapt or restrict original constructs. McGinn and Keros (2002) relied on such a strategy to inductively characterize the micro-logics and activities through which participants make sense of their interactions. The authors distinguish three different improvisation logics of exchange during dyadic transactions: "opening-up", "working together" and "haggling" (as opposed to the distributive/integrative categories conventionally distinguished in negotiation literature). They also paid particular attention to asymmetric interactions where participants relied on different logics of improvisation.

Other researchers used prior categories devised on some external basis (an a priori theory or analytical framework, a standardized protocol). Gephart (1993) used Garfinkel's ethnomethodological typologies to characterize the sensemaking practices and rules used by participants during an inquiry into an accident. Allard-Poesi (2001) utilized a standardized coding protocol, derived from Huff's (1990) protocol for cognitive mapping, to capture the influence beliefs expressed by group members during their interactions. 
Orton (2000) used an iterative-grounded approach to analyze the 1976 reorganization of U.S. Intelligence. This strategy consists of simultaneously gathering and comparing different theoretical models and emerging data sets. The archival data were compressed into a narrative of 91 stories. Orton then created an analytical matrix in which ten different theoretical perspectives were compared with the 91 stories so as to appreciate their explanatory capacity. The 91 stories were compressed into 50 stories and the analytical matrix was used to sort the 50 stories into the 10 perspectives that explained them best. Those stories were finally paired with Weick's theory of organizing whose explanatory power was compared with that of the initial theoretical framework.

To ground: (of a ship) (cause to) touch the sea bottom; (of aircraft, airmen) compel to stay on the ground.

In sum, sensemaking research relies heavily on systematic comparison approaches (between data, or between data and prior categories). Such extensive use of systematic comparison expresses the inquirer's intention of revealing regularities and systematic associations, not in the content of the meaning people attach to their experience, but in the structuring process of sensemaking and organizing. Researchers seek to grasp the meanings people use and create in order to understand the reality in their own native terms (emic analysis). At the same time, they seek to characterize the sensemaking process with the aim of producing general, possibly law-like statements about human social organization (etic analysis, Silverman, 1993: 24)

With interpretivists and symbolic interactionists, researchers studying sensemaking processes are then faced with a fundamental paradox: defining reality as essentially mental and socially constructed, yet seeking to disengage from that experience and objectify it, "celebrating the permanence and priority of subjective and socially constructed experience and still struggling 
with drawing a line between the object of inquiry (sensemaking) and the investigator" (Schwandt, 1994: 118).

As a result, sensemaking research tends to ossify and undermine, or even lose sight of, the very conception of sensemaking it seeks to convey. Grounded sensemaking models privilege sequentiality over fluidity (see Gioia et al.'s -1994- four stage model of sensemaking during strategic change in Academia; Thomas et al.'s -2001- model of strategic learning). This research perspective assumes and focuses on shared meanings, values and intentions, and sometimes omits divergences, cryptic or ambivalent meanings and unclear preferences (see Gephart, 1993; 1997; Gioia et al., 1994; 1996; Thomas et al., 2001). It looks at quasideterministic influence relationships in a sensemaking context and participants' perceptions and intentions (McGinn and Keros, 2002; Allard-Poesi, 2001; Gioia et al., 1996) and neglects the emergent, creative aspect of sensemaking. As it is difficult to grasp something that does not 'exist', it concentrates on the making and structuring of sense and overlooks nonsensemaking and the destruction of meaning. In sum, sensemaking research approaches tend to transform the sensemaking bricolage into a standardized production.

According to Schwandt (1994), the paradox of the 'objective science of subjectivity' is not the privilege of particular approaches (sometimes called 'objectivist' or 'grounded' approaches) to interpretivism, but lies at the heart of the interpretive project. Consistently with their phenomenological and interactive hypothesis, interpretivists consider the knowledge they elaborate as a construction: an "interpretation of how people construe, construct and create meanings out of the events and phenomena through prolonged, complex processes of social interaction involving history, language and action (Schwandt, 1994: 118)". The goal is not to discover reality and the laws underlying it, but to develop an understanding, a Verstehen, of the actors' definitions of the situation. This does not put an end, however, to the question of the nature of such Verstehen. 
Interpretivists suggest different versions of how to develop such an understanding. Symbolic interactionists like Mead and Blumer, and other interactionists (see Silverman, 1993) seek explicitly to explain the world of the native people through a social theory. This research program requires that the researcher actively enters the world of the people being studied in order to see the situation as it is seen by the actors, to observe what they take into account, how they interpret what they take into account (Blumer, 1969: 56), how they behave and interact, and in which context (Schwandt, 1994: 124). This "thick" description will be taken as a point of departure for formulating an explanatory interpretation of what the actors are doing.

Geertz's interpretive anthropology proposes searching out and analyzing "the symbolic forms -words, images, institutions and behaviors - in terms of which, in each place, people actually represent(ed) themselves to themselves and to one another" (Geertz, 1983: 58, in Schwandt, 1994: 123). The ethnographic analysis is not aimed at discovering people's meanings but at "inscribing, writing and fashioning meanings". The Verstehen achieved will be a secondorder, third-order interpretation of the respondents' interpretations, built upon the interplay of experience-near and experience-distant concepts and will offer a theoretical formulation of what this means for social life in general (Geertz, 1973, in Schwandt, 1994).

Although their relying on different theoretical and methodological backgrounds, interpretivists (and in particular symbolic interactionists) insist "good ethnography [...] should not be limited to a set of descriptions of how people behave in different settings. On the contrary, ethnography shares the social science program of producing general, possibly even law-like statements about human social organization (Silverman, 1993: 49)".

Escaping the paradox of the 'objective science of subjectivity' is not an easy task. It implies that we reconsider our interpretive/sensemaking strategies together with the status we assign to the knowledge we elaborate through these. 


\section{Re-engaging in Sensemaking}

The paradox of the "objective science of subjectivity" in sensemaking research may be understood as resulting from two particular contradictions. First, researchers consider the members of an organization as actively constructing their reality through their interactions and experiences of the world, but they regard themselves as able to disengage from that experience and grasp it. Secondly, researchers define social reality as fluid, precarious, indeterminate and fundamentally tensional, yet disengage from that indeterminacy and rely on methodological approaches that seek to establish regularities, systematic associations and sequentiality in the sensemaking process.

In other words, sensemaking research may be said not to have fully considered the consequences of the "situated", socially constructed and precarious character of sensemaking (Alvesson and Karreman, 2000a). If meanings are fundamentally situated and actively constructed by interacting people, this should also be the case of knowledge created by the inquirer. Studying sensemaking becomes an active, purposeful and intersubjective sensemaking process in itself.

Acknowledging this view and translating it into our research approaches is not an easy enterprise. As a beginning, we present here two different routes that may enable us to reengage in or against (rather than disengage from) sensemaking processes.

\section{Deconstructing sensemaking}

Underlining the undecidability and constitutive aspect of language, postmodernists invite us to consider the study of sensemaking processes as a writing/reading process, implying both inscription and undecidability. Fully acknowledging this view implies that we try to resist “our" closure of meanings when writing (on) sensemaking processes in organizations. 


\section{Writing sensemaking processes}

Postmodernists underline that language, by providing particular unities and distinctions, structures our experience of the world and produces a version of social realities to the exclusion of others (Chia, 2000: 513-514). Far from mirroring reality, language inscribes order on the world so that it becomes thinkable and controllable. What appears to us as 'organizations', 'individuals', 'environments', or 'meanings' and 'representations' are in fact reified entities resulting from prior linguistic organizing processes (Chia, 1995: 592). Similarly, language cannot be said to express our subjectivity (our thoughts, perceptions and feelings). "As discourses structure the world they at the same time structure the person's subjectivity, providing him/her with a particular social identity and way of being in the world" (Alvesson and Deetz, 1996: 205).

As structured by language, sensemaking and cognition may be understood as a socially constructed process of ordering, structuring and organizing (Chia, 1995). As such, sensemaking is similar to Derrida's Writing: "the process by which human agents inscribe organization and order on their environment" (Cooper, 1989: 484), "the technology developed as a consequence of the 'taxonomic urge' to fix the flux and flow of human experience in temporal and spatial terms" (Chia, 1995: 597).

Such a constitutive conception of language and sensemaking is not so different from those defended by sensemaking research. Weick (1995: 197-8) in fact urges us "stamp out nouns" because they conceal the fact that organizing is about flows, change and processes and "to stamp in verbs" if we want to get closer to the nature of organizing.

In the postmodern perspective, however, this conception of language and sensemaking practices has been pushed one step further to apply to the researcher's methods and activities. Postmodernists regard scientific production as the result of a writing process that is governed and influenced by the rules of language formation and by the context in which such 
discourses are expressed (Gergen, 1992: 213). The socio-constructionists' goal of grasping people's meanings and describing the processes by which they create, negotiate and sustain those meanings is thus fundamentally misleading. The study of sensemaking processes becomes a writing/reading process, a re-creation by a "reader/researcher" which inscribes, through the methodologies used, its own order on the indeterminacy of sensemaking.

\section{Opening up the undecidability of meanings}

Postmodern thinking also stresses the fundamental undecidability of sensemaking: its continuous, paradoxical movement that both constitutes meaning and refuses its singular grasp. Postmodernists, along with poststructuralists, reject the "myth of structure", the idea that language is structured around mutually exclusive opposites that permit a singular grasp of their meanings (a logic of difference, Cooper, 1989: 486; Cooper and Burrell, 1988: 94). Following Derrida, they underline that language is animated by differance, that is "a form of self-reference in which terms contain their own opposites and thus refuse any singular grasp of their meaning" (Cooper and Burrell, 1988: 98). To write or say something implies placing in the margins or excluding a supplement meaning that will always contaminate and corrupt the privileged one (Cooper, 1989: 486-487). Through this continuous and autonomous movement, language is 'undecidable', indeterminate.

Sensemaking, which takes place in actions and interactions mainly through language, becomes a paradoxical movement of construction and self-negation. It exists "in continual fluidity, with its own negation, paradox and ambiguity being its essential qualities" (Linstead, 1993: 60). This implies shifting the emphasis away from oppositional and interpretive strategies towards those processes that shape both meanings and equivocality.

Such a research program is not so different from Weick's: his studies of the Mann Gulch Disaster (1993b) and the Tenerife Air Disaster (1990) focus on the understandings people develop as events unfold and at the same time on the destruction or ossification of collective 
meaning. Sensemaking research, however, by relying extensively on constant comparison methods, implies the production of divisions and distinctions, which tend to give precedence to order, unity, identity and regularity over inconsistency, fragmentation, ambiguity and indeterminacy.

Pushing this constitutive and undecidable conception of language further, postmodernists invite us to define our sensemaking of sensemaking as a writing process that, as such, is animated by the continual and paradoxical logic of differance, implying both inscription and undecidability (Alvesson and Sköldberg, 2000: 151). Accordingly, they propose that we abandon any "objective science of subjectivity" and try to "open up the indeterminacy that modern social science, everyday conceptions, routines and practices have closed off" (Alvesson and Deetz, 1996: 210). The aim is, in fine, to denounce the illusion of control and referentiality of language and research, and to provoke new interpretations: Our sensemaking of sensemaking becomes a "fiction", which, through the reflexivity and re-creation it involves, may open up new possibilities for action (Chia, 2000) and sensemaking. This implies resisting the closure of meaning and authority, and giving the reader back the freedom to rewrite our own writings/readings. Here, postmodernists invite us to adopt deconstructive and reflexive approaches (among others).

Deconstructive approaches aim to show that discourses are constructed around dualism and opposites in which one of the terms (usually the one expressing stability, order or unity) dominates the other, but that at the same time, because of differance and supplementarity, their meanings escape the authors of these discourses (Cooper, 1989). Deconstruction reveals the inherent contradictions of "texts" (inscriptions): the narrative practices used to discipline particular meanings, as well as their ambiguity and polysemous nature (Brown, 2000).

Brown (2000) deconstructs the Report on the Inquiry into Allitt's attacks on children in Ward 4 at Grantham and Kesteven Hospital in the U. K. ${ }^{\text {ii }}$ He shows that the report depicts Allitt as 
outwardly normal (normalizing without demonizing): No one noticed Allitt was unusual because there was nothing unusual to notice. This authorial strategy contributes to the depiction of the general failure to detect Allitt's activities sooner as plausible. This general failure is further accounted for by the medical staff's incapacity to recognize a general pattern in the unfolding events (observing without discerning). Such an account appears plausible and meaningful because it is consonant with current theories of sensemaking. The initiation of a pattern search does not guarantee a pattern recognition: this search may occur before any identifiable pattern has emerged; it may be restricted and guided by previous professional frames and routines of interpretation; it may fail as the potential sensemakers face a highcomplexity and high-information environment and lack the opportunity and time to collectively make sense of what is happening. The premise that Allitt was normal, together with the account of how the medical staff plausibly failed to recognize a general pattern in the events, serve to alleviate criticism of the doctors, nurses and administrators that worked with her (absolving without blaming).

Brown's deconstruction uncovers the authorial strategies used to reduce the anxiety provoked by Allitt's actions and to re-establish the legitimacy of the medical institution. At the same time, it shows how theories of sensemaking contributed to the verisimilitude of the report and the depolitization of Allitt's case. Brown proposes another plotline, which invites the reader to adopt a skeptical attitude towards the Allitt Inquiry, Brown's report, and the (political) role of our theories of sensemaking.

In sum, postmodernists propose that we reopen the indeterminacy that 'modern' science and methods have closed off. This proposal, however, refuses any claim to universal knowledge and legitimacy, and only suggests a posture of local resistance, behind which it seems difficult to find reasons for acting, knowing (Parker, 1993; Calàs and Smircich, 1999) and making sense. In this view, Weick (1995: 38) points out that "the destructive side of 
deconstructionism is the undermining the faith and beliefs necessary to get [the researcher's or the actors', our addition] sensemaking started". To the posture of resistance proposed by postmodernists, Weick favors James and Dewey's pragmatist philosophy, which invites us to engage in participative action research.

\section{Co-researching sensemaking}

Underlining a self-deterministic conception of people and a socio-constructionist view of social reality, participative action research proposes us that we fully engage in sensemaking and sensemaking research with (vs. on or against) the members of the organization.

\section{Making sense with organization members}

By participative action research ${ }^{\mathrm{iv}}$, we refer here to a set of research approaches whereby "some of the people in the organization, group or community under study participate actively with the professional researchers throughout the research process from the initial design to the final presentation of results and discussion of their action implications" (Whyte et al., 1991: 20): Cooperative inquiry (Heron, 1996; Reason and Heron, 1986), human inquiry (Reason, 1994b), pragmatist action research (Levin and Greenwood, 1998) and other related approaches (participatory action research conducted in western organizations, e.g. Whyte, 1991), in particular.

Despite their different theoretical and philosophical underpinnings, these approaches agree to view social reality and knowledge as elaborated in the interactions people engage in with each other and with the world surrounding them. While orthodox social science methods exclude the human subjects from the research process (and thus invalidate any claim the methods have to be a science of persons, Reason, 1994a: 325), participative approaches emphasize participation and interactions both as an ontological condition and as a research strategy. 
First of all, the individuals are considered as self-determining: to some degree actually (and to a greater degree potentially), they are authors of their actions (Reason, 1994a). What participants do, what they experience as part of the research must be determined by them to a significant degree. Ideally, the researchers and participants are all co-researchers: "Together, the professional researchers and the stakeholders define the problems to be examined, cogenerate relevant knowledge about them, learn and execute social research techniques, take actions, and interpret the results of actions based on what they have learned" (Greenwood and Levin, 1998: 4).

In addition, relying on Dewey's pragmatist philosophy and Lewin's action research principles, participative approaches consider that the only real sources of knowledge and meanings are to be found in people's active experience of the world. Already pervading Weick's conception of sensemaking, this idea is strongly promoted in participative approaches to apply to the researchers' activities and knowledge. Participative approaches rule out conventional interpretive positions that imagine the inquirer taking a neutral or objective stance on the question and the situation under study. The logic of inquiry implies "a struggle to make an indeterminate situation into a more positively controlled one through an inquiry process where reflection and action are directly linked" (Greenwood and Levin, 1998: 78). The outside researcher then inevitably becomes a participant.

In this cogenerative process, high value is placed on the diverse and sometimes contradictory representations participants may have of the situation. Relying on different knowledge and experiences, the local participants and the researchers necessarily have different conceptions of the problem to be solved and the situation under study. On the other hand, collaborative processes have to face problems of inclusion/exclusion, influence and power relationships (Reason, 1994a). It is rarely possible to reach full consensus and reciprocity on the actions to be undertaken and the meanings developed. Nor is this desirable. The diverse understandings 
and the dynamic tension they lead to are understood as crucial resources for the development of creative solutions and meanings (Greenwood and Levin, 1998: 11). Participative approaches therefore focus on the creation of research designs and processes that avoid communicative domination of the insiders or researchers and foster dialogue, confrontation and debates between co-researchers (e.g. search conferences, leadership groups, task force meetings, collective reflection sessions, Bartunek, 1993).

This practice-oriented and collaborative process is aimed at producing workable solutions to the problem under study, as well as helping co-researchers make sense of these tangible results. Participation and confrontation are intended to reveal the combination of practical reasoning and socially constructed meanings held by local people and to throw a bridge from this local knowledge to scientific knowledge as a way of creating both new local meanings and scientific understandings (Greenwood and Levin, 1998: 89-99; 111). This co-generative learning is of course never final as it relies on continuous, dialogical and practice-oriented interpretive processes (Greenwood and Levin, 1998: 87).

Participative action research invites us then to fully engage in sensemaking processes with the participants of the organization under study, and to reflect on these processes with them. It substitutes a fully engaged and collaborative attitude for those of neutrality or objectivity assumed by interpretive research or of distanced resistance proposed by deconstructionists.

\section{Writing sensemaking with insiders}

In participative action research, research publications on the sensemaking processes that took place should ideally be produced jointly by the insiders and the outsiders (Greenwood and Levin, 1998; Bartunek, 1993). As the co-researchers are likely to experience and understand the sensemaking and learning process differently, they all can make important contributions to building theory about these processes. Such co-generated reports (taking the form of case 
studies, with detailed discussions of the processes that the participants went through in generating the knowledge and meanings during the intervention) can also help participants and researchers to increase their understandings of the change process. In 1993, Bartunek underlined: "Action researchers and participants interpreting and writing together about their joint endeavors is a fairly logical next step in the participatory action research process" (p. 1231).

This logical step may however be quite complex and difficult to take. It requires the researchers to leave room for the interpretations of the local participants and to contend with the norms of academic publications that may not be ready to accept such multi-voiced accounts. Ten years after Bartunek's call, publications of this kind are still rare in organization studies. The Mandragón research conducted by Greenwood and his colleagues (see Greenwood and Levin, 1998; Whyte et al., 1991) may be taken here as illustrative of this 'participative sensemaking' perspective and of the problems it runs up against.

The Mandragón research took place between 1982 and 1986 in the Fagor Cooperative Group, the largest and best-known cooperative group in the area of Mandragón, located in the Spanish Basque Country. Initiated by Whyte, Greenwood and the Fagor personnel manager, González, the project was intended to develop the internal social research capacity of the Fagor Group. The process began with mutual visits and a summer course in action research taught by Greenwood to 15 members of the Fagor Group. The participants, primarily drawn from the central personnel department, decided to continue the project. They were worried about the future of the cooperatives, stating that many newly recruited members were not committed to cooperative values, and that under stress, the system would not be able to adapt. An extensive interviewing project, another summer course, a series of focus groups and a lengthy co-writing process during which two books about the project were written, followed. 
While the participants initially interpreted the 'problem' as a lack of commitment to cooperative values, they gradually came to believe there was no fundamental crisis of cooperative values. However, the research produced a great deal of information about dissatisfaction with the cooperatives' operations. The researchers began to reflect on their own roles and practices. It became then clear that many of the complaints were about the practices of personnel departments: they applied rules impersonally to members, contradicting the cooperatives' principles of debate, dialogue and confrontation. In particular, when some kinds of problems surfaced, personnel departments and local managers treated them as a matter of governance, to be dealt with by the organizational rules, statutes and procedures. Participants outlined a contradiction between their lives and understandings as workers (who valued dialogue, contestation and debate), and their lives and understandings as managers (who extracted all conflict from work relations and treated it institutionally). In sum, the project led the participants to develop a new understanding and conceptualization of the processes and culture of the organization.

Although providing many details about the sensemaking process, this case study lacks data on the intervention and its positive and negative effects. The dialogic processes between the insiders' and outsiders' understandings in particular, are not described. So while it is clear that sensemaking processes occurred in the Fagor experience, the reader has a problem 'making sense' of what happened.

Participative action research seems a fruitful route to pursue for sensemaking research. But it still has to find a place in organizational studies. Explicitly underlining the conceptual contributions appears to be a necessary condition for participative approaches to contribute to academic dialogue (Bartunek, 1993). 


\section{Conclusion}

Contributing to the socio-constructionist perspective in organization studies, Weick's work underlines a conception of sensemaking as a subjective and purposeful activity that takes place in the micro-activities of interactions and conversations between the members of the organization. Although departing from the structuro-functionalist approach of conventional cognitive theories, research on sensemaking processes nonetheless aims to establish 'objective' knowledge on sensemaking. It relies extensively on micro/interpretivist data gathering techniques and on systematic comparison approaches to grasp the meanings people attach to their experiences (first-order understanding) and reveal regularities and systematic associations in the structuring processes of sensemaking and organizing (second-order analysis). While celebrating the priority of subjective and socially constructed human experience, researchers seek to disengage from that experience and objectify it. In so doing, researchers not only contradict their own conception of sensemaking, but also undermine, if not lose sight of, the very conception of sensemaking they want to convey.

Bypassing this paradox is not an easy task. It implies that we "drop our heavy methodological tools" (systematic comparison techniques in particular) that tend to disengage us from our prior subjective experience of the sensemaking processes we seek to study. It also implies that we re-engage in sensemaking, understood as an active, purposeful and intersubjective process in itself. Two routes have been tentatively suggested in this way. The postmodern route, on the one hand, invites us to engage against our sensemaking process so as to uncover the precarious, undecidable character of sensemaking in organizations. The pragmatist/participative route, on the other hand, encourages us to engage in sensemaking with the members of the organization under study and so fully recognize the socially constructed aspect of sensemaking activities. 
Those proposals are certainly not definite answers to the paradox of sensemaking research.

Deconstructive approaches imply a resistance, i.e. an anomic attitude which appears to make it difficult to find reasons for acting, knowing and making sense. They also suggest that we primarily engage against ourselves, an attitude that may be regarded as narcissistic and disengaged from the mode of living we are trying to understand (Weick, 2002: 894-895).

As a way both to distance themselves from objectivist interpretive method and to avoid this postmodern trap, some researchers favor combination of interpretive strategies. Alvesson and Sveningsson (2003) combine hermeneutic and post-structuralist reading to analyze the managers' talks about leadership and management at work in a large knowledge-intensive company. In the hermeneutic reading, the managers' discourses and the pre-understanding the researcher brings into the research are analyzed in-depth so that the interpretation uncovers the unity and coherence of meanings as well as their variations and contradictions. Relying on post-structuralism, the authors carefully consider the organizational context, discourses and policies participants are engaged in, in order to highlight the inherent contradictions and conflicting demands of their situations. Although departing from conventional deconstructionist approach, such reflexive methodology necessarily implies the researcher to disengage from his/her sensemaking process as s/he qualifies, challenged and developed her/his prior understanding and sources of inspiration. As far as the constitutive and undecidable character of sensemaking and discourses are taken seriously, this resistance posture may, however, be both inescapable and necessary.

Participative approaches on the other hand, may be said to rely on a naïve conception of social reality. They tend to undermine the power and influence relationships that take place in the organization, the ambivalent or contradictory interests of participants, which may slow down or impede the development of a participative approach. They neglect the practical difficulties that the co-researchers may encounter as they strive to collectively make sense of 
and 'write' their sensemaking experiences. If this co-writing may foster participants' sensemaking and learning, it requires them to leave room for the others' voices and to reach consensus on a specific 'writing'. Whether such a collective enterprise is possible, and what kind of text it will arrive at, are open questions.

Though not without difficulties, deconstructionist and participative approaches offer us alternative (and even complementary) ways of re-engaging in sensemaking. They may thereby contribute to different forms of knowledge on sensemaking processes: a critical, opened-up interpretation for deconstructive (or reflexive) approaches; a 'living', intersubjective interpretation for participative approaches.

While focusing on reflexivity (Calás and Smircich, 1999; Weick, 1999; 2002), organization theorists have placed much emphasis on the theoretical tools and frameworks we use to make sense of organizational life. In so doing, they have tended to lose sight of the fact that our experience and research are equally structured by the methodological tools we use to uncover and communicate the 'objects' under study. As you change your methodological tools, you change the way you 'sculpt' reality (Weick, 1993a). This encourages us to use or invent new tools so as to make sense differently.

\section{Notes}

I would like to thank anonymous Organization reviewers for their critiques, questions and suggestions, which helped me structure and develop further the arguments of the paper. An earlier version of this article was presented at the EIASM $8^{\text {th }}$ International Workshop on Managerial and Organizational Cognition, ESCP, Paris $\left(30^{\text {th }}, 31^{\text {st }}\right.$ May, $1^{\text {st }}$ June 2001). I would like to thank participants for their encouragements and suggestions on the earlier draft of the paper. This work has been supported by a grant of the Institut de Recherche en Gestion, Université Paris-Val-de-Marne. Thanks to Joan Potter for her assistance in language editing and checks.

i For instance Dutton's theory of identity or Morgan, Pondy and Mittroff's framework of symbolic processes in organizations (in Gioia et al., 1991; 1994; 1996); Garfinkel's ethnomethodogical approach (in Gephart, 1993).

ii Brown (2000), Brown and Jones (2000), and Alvesson and Sveningsson's (2003) studies are taken here as illustrative of alternative approaches to sensemaking. The third and end sections are devoted to these alternative approaches.

iii The Allitt Inquiry was an independent tribunal of inquiry initiated in May 1993 by the United Kingdom's Secretary of State for Health to enquire into the circumstances leading to the deaths of four children and injuries to nine others on Ward 4 at Grantham and Kesteven General Hospital during the months February to April 1991. The report narrates how the child died and collapsed, as well as the doctors and nurses' responses to these events. It relates how it seemed to the clinical staff that what had happened, while unusual, could nevertheless be explained on the basis of each child's medical history (Brown, 2000). 
iv These approaches are sometimes referred to as Participatory Action Research. This term was originally used to describe a form of liberationist inquiry in underprivileged parts of the Third World and the developed West, which was primarily aimed at the "Enlightment and awakening of common people" (Reason, 1994a). To avoid confusion, we keep the original terminology and use the term participative/cooperative action research to refer to the collaborative approaches here mentioned.

\section{References}

Allard-Poesi, Florence (1998) 'Representations and Influence Processes in Groups: Towards a Socio-cognitive Perspective on Cognition in Organization', Scandinavian Journal of Management, 14(4): 395-420.

Allard-Poesi, Florence (2001) 'Collective Representations: Decision-Making in a Working Group', in B. Hellgren and J. Löwstedt (eds) Management in the Thought-Full Enterprise, European Ideas on Organizing, pp. 214-239. Bergen: Fagbokforlaget.

Alvesson, Mats and Deetz, Stanley (1996) 'Critical Theory and Postmodernism Approaches to Organizational Studies', in S. R. Clegg, C. Hardy and W. Nord (eds) Handbook of Organizational Studies, pp. 191-217. London: Sage Publications.

Alvesson, Mats and Karreman, Dan (2000a) 'Taking the Linguistic Turn In Organizational Research: Challenges, Responses, Consequences', The Journal of Applied Behavioral Science, 36(6): 136-158.

Alvesson, Mats and Karreman, Dan (2000b) 'Varieties of Discourse: On the Study of Organizations through Discourse Analysis', Human Relations, 53(9): 1125-1149.

Alvesson, Mats and Sköldberg, Kaj (2000) Reflexive Methodology, New Vistas for Qualitative Research. London: Sage.

Alvesson, Mats and Sveningsson, Stefan (2003) 'Good Visions, Bad Micro-management and Ugly Ambiguity: Contradictions of (Non-)Leadership in a Knowledge-Intensive Organization', Organization Studies, 24(6): 961-988. 
Bartunek, Jean (1993) 'Scholarly Dialogues and Participatory Action Research', Human Relations, 46: 1221-1233.

Beyer, Janice M. (1981) 'Ideologies, Values and Decision Making in Organizations', in P.C.

Nystrom and W.H. Starbuck (eds) Handbook of Organizational Design, 2, pp. 166-201. London: Oxford University Press.

Blumer, Herbert (1969) Symbolic Interactionism: Perspective and Method. Englewood Cliffs, NJ: Prentice Hall.

Brown, Andrew (2000) 'Making Sense of Inquiry Sensemaking', Journal of Management Studies, 37(1): 23-44.

Brown, Andrew and Jones, Matthew (2000) 'Honourable Members and Dishonourable Deeds: Sensemaking, Impression Management and Legitimation in the 'Arms to Irak Affair', Human Relations, 53(5): 655-689.

Calás, Marta and Smircich, Linda (1999) 'Past Postmodernism? Reflections and Tentative Directions', The Academy of Management Review, 24(4): 648-671.

Chia, Robert (1995) 'From Modern to Postmodern Organizational Analysis', Organization Studies, 16(4): 579-604.

Chia, Robert, (2000) 'Discourse Analysis as Organizational Analysis', Organization, 7(3): 513-518.

Cooper, Robert (1989) 'Modernism, Post Modernism and Organizational Analysis 3: The Contribution of Jacques Derrida', Organization Studies, 10(4): 479-402.

Cooper, Robert and Burrell, Gibson (1988) 'Modernism, Postmodernism and Organizational Analysis: An Introduction', Organization Studies, 9(1): 91-112.

Denzin, Norman (1970) The Research Act in Sociology, London: Butterworth.

Doise, Willem and Moscovici, Serge (1994) Conflict and Consensus, a General Theory of Collective Decisions. London: Sage. 
Easterby-Smith, Mark, Crossan, Mary and Nicolini, Davide (2000) 'Organizational Learning:

Debates Past, Present and Future', Journal of Management Studies, 37(6): 783-797.

Eisenhardt, Kathleen, Kahwajy, Jean and Bourgeois, L. J. III (1997) 'Conflict and Strategic

Choice: How Top Management Disagree', California Management Review, 39(2): 42-62.

Fiol, C. Marlene (1994) 'Consensus, Diversity and Learning in Organizations’, Organization Science, 5(3): 403-420.

Geerzt, Clifford (1973) The Interpretation of Cultures: Selected Essays. New York: Basic Books.

Geerzt, Clifford (1983) Local Knowledge: Further Essays in Interpretive Anthropology. New York: Basic Books.

Gephart, Robert (1997) 'Hazardous Measures: An Interpretive Textual Analysis of Quantitative Sensemaking during Crisis', Journal of Organizational Behavior, 18: 583-622.

Gephart, Robert (1993) 'The Textual Approach: Risk and Blame in Disaster Sensemaking', The Academy of Management Journal, 36(3): 1465-1514.

Gergen, Kenneth (1992) 'Organization Theory in the Postmodern Era', in M. Reed and M. Hughes (eds), Rethinking Organizations, pp. 207-226. London: Sage.

Gioia, Dennis and Chittipeddi, Kumar (1991) 'Sensemaking and Sensegiving in Strategic Change Initiation', Strategic Management Journal, 12: 443-448.

Gioia, Dennis and Thomas, James (1996) 'Identity, Image, and Issue Interpretation: Sensemaking during Strategic Change in Academia', Administrative Science Quarterly, 41: $370-403$.

Gioia, Dennis, Thomas, James, Clark Shawn and Chittipeddi, Kumar (1994) 'Symbolism and Strategic Change in Academia: The Dynamics of Sensemaking and Influence', Organization Science, 5(3): 363-383. 
Glaser, Barney and Strauss, Anselm (1967) The Discovery of the Grounded Theory. Chicago: Aldine.

Goetz, Judith and LeCompte, Margaret (1981) 'Ethnographic Research and the Problem of Data Reduction', Anthropology and Education Quarterly, 12: 51-70.

Greenwood, Davydd and Levin, Morten (1998) Introduction to Action Research, Social Research for Social Change. London: Sage.

Hedberg, Bo L. T. (1981) 'How Organizations Learn and Unlearn', in P. C. Nystrom and W.H. Starbuck (eds) Handbook of Organizational Design, 1, pp. 3-27. Oxford: Oxford University Press.

Hellgren, Bo and Löwstedt, Jan (2001) Management in the Thought-Full Enterprise, European Ideas on Organizing. Bergen: Fagbokforlaget.

Heron, John (1996) Co-operative Inquiry: Research into the Human Condition. London : Sage.

Huberman, Michael and Miles Matthew (1984) Qualitative Data Analysis: A Source Book on New Methods. London: Sage.

Huff, Anne S. (1990) Mapping Strategic Thought. New York: Wiley.

Huff, Anne S. (1997) 'A Current and Future Agenda for Cognitive Research in Organizations', Journal of Management Studies, 34(6): 947-952.

Knorr-Cetina, K. D. (1981), 'The Microsociological Challenge of Macrosociology : Toward a Reconstruction of Social Theory and Methodology', in K. D. Knorr-Cetina and A. V. Cicourel (eds) Advances in Social Theory and Methodology, pp. 1-47. Boston, MA: Routledge and Kegan Paul.

Lincoln, Yvonna S. and Guba, Egon G. (1985) Naturalistic Inquiry. London: Sage.

Linstead, Steve (1993) 'Deconstruction in the Study of Organizations', in J. Hassard and M. Parker (eds) Postmodernism and Organization, pp. 49-70. London: Sage. 
McGinn, Kathleen and Keros, Angela (2002) 'Improvisation and the Logic of Exchange in Socially Embedded Transactions', Administrative Science Quarterly, 47: 442-473.

Nemeth, Charlan (1997) 'Managing Innovation: When Less is More', California Management Review, 40(1): 59-74.

Orton, James (2000) 'Enactment, Sensemaking and Decision Making: Redesign Processes in the 1976 Reorganization of US Intelligence', Journal of Management Studies, 37(2), 213-234. Parker, Martin (1993), 'Life After Jean-François', in J. Hassard and M. Parker (eds) Postmodernism and Organization, pp. 204-213. London: Sage.

Poole, Peter, Gioia, Dennis and Gray, Barbara (1989) 'Influence Modes, Schema Change, and Organizational Transformation', The Journal of Applied Behavioral Science, 25(3): 271-289.

Reason, Peter (1994a) 'Three Approaches to Participative Inquiry', in N. Denzin and Y. Lincoln (eds.) Handbook of Qualitative Research, pp. 324-339. London: Sage.

Reason, P. (1994b) Participation in Human Inquiry. London : Sage.

Reason, Peter and Heron, John (1986) 'Research with People: The Paradigm of Co-operative Experiential Inquiry', Person Centred Review, 1: 456-475.

Schwandt, Thomas (1994) 'Constructivist, Interpretivist Approaches to Human Inquiry’, in N. K. Denzin and Y. S. Lincoln (eds) Handbook of Qualitative Research, pp. 118-137. London: Sage.

Schutz, A. (1967) Collected Papers, vol. 1. The Hague: Martinus Nijhoff.

Silverman, David (1993) Interpreting Qualitative Data, Methods for Analysing Talk, Text and Interaction. London: Sage.

Spradley, James (1979) The Ethnographic Interview. New York: Holt Rinehart and Winston. Sproull, Lee S. (1981) 'Beliefs in Organizations', in P.C. Nystrom and W.H. Starbuck (eds) Handbook of Organizational Design, 2, pp. 203-223. Oxford: Oxford University Press. 
Strauss, Anselm and Corbin, Juliet (1990) Basics of Qualitative Research, Grounded Theory, Procedures and Techniques. London: Sage.

Thomas, James, Clark, Shawn and Gioia, Dennis (1993) 'Strategic Sensemaking and Organizational Performance: Linkages among Scanning, Interpretation, Actions and Outcomes', The Academy of Management Review, 36(2): 239-70.

Thomas, James, Sussman, Stephanie and Henderson, John (2001) 'Understanding "Strategic learning": Linking Organizational Learning, Knowledge Management, and Sensemaking', Organization Science, 12(3): 331-345.

Tsoukas, Haridimos and Vladimirou, Eft (2001), 'What is Organizational Knowledge?', Journal of Management Studies, 38(7): 973-993.

Van Maanen, John (1979) 'The Fact of Fiction in Organizational Ethnography', Administrative Science Quarterly, 24: 539-550.

Waterman, R. H., Jr. (1990) Adhocracy: The Power to Change. Memphis, TN: Whittle Direct Books.

Weick, Karl (1979) The Social Psychology of Organizing. New York: Random House.

Weick, Karl (1990) 'The Vulnerable System: An Analysis of the Tenerife Air Disaster', Journal of Management, 16(3). Reprinted in K. Weick (2001), Making Sense of the Organization, pp. 125-147. Oxford: Blackwell.

Weick, Karl (1993a) 'Sensemaking in Organizations: Small Structures with large Consequences', in J. K. Murnigham (ed.) Social Psychology in Organizations: Advances in Theory and Research. Englewoof Cliffs, NJ: Prentice Hall. Reprinted in K. Weick (2001) Making Sense of the Organization, pp. 5-31. Oxford: Blackwell.

Weick, Karl (1993b) 'The Collapse of Sensemaking in Organizations: The Mann Gulch Disaster', Administrative Science Quarterly, 38(4). Reprinted in K. Weick (2001) Making Sense of the Organization, pp. 100-124. Oxford: Blackwell. 
Weick, Karl (1995) Sensemaking in Organizations. London: Sage.

Weick, Karl (1998) 'Improvisation as a mindset for Organizational Analysis', Organization Science, 9: 549-555.

Weick, Karl (1999) 'Theory Construction as Disciplined Reflexivity: Tradeoffs in the 90s', The Academy of Management Review, 24(4): 797-806.

Weick, Karl (2001) Making Sense of the Organization. Oxford: Blackwell.

Weick, Karl (2002) 'Real-Time Reflexivity': Prods to Reflection', Organization Studies, 23(6): 893-898.

Wenger, Etienne (2000) 'Communities of Practice and Social Learning Systems' Organization, 7(2): 225-246.

Whyte, William Foote (1991) Participatory Action Research. London: Sage.

Whyte, William Foote, Greenwood, Davydd and Lazes, Peter (1991) 'Participatory Action Research, Through Practice to Science in Social Research', in W.F. Whyte (ed.) Participatory Action Research, pp. 19-55. London: Sage.

Florence Allard-Poesi is Assistant Professor in Management at University of Paris XII Valde-Marne and member of the Institut de Recherche en Gestion. She received her Ph.D. on the nature and emergence process of collective representations in working groups at the University of Paris-Dauphine. Her research interests are in collective sensemaking, innovation and influence processes in groups and leadership. She currently works on methodological and epistemological issues related to the study of sensemaking processes in organizations. She has recently completed, in collaboration with Professor Véronique Perret, a participative action research that was aimed at elaborating a strategic project for a child welfare non-profit organization.

Adress: Institut de Recherche en Gestion, Université Paris XII Val-de-Marne, Place de la Porte des Champs, Route de Choisy, 94000 Créteil, France. email : allard-poesi@univparis 12.fr 